\title{
A FUZZY MULTICRITERION Q-ANALYSIS MODEL FOR INTERNATIONAL LOGISTIC-PARK LOCATION SELECTION
}

\author{
Junn-Yuan Teng \\ Associate Professor, Dept. of Industrial Management, Huafan University, Taipei, Taiwan, R.O.C. \\ Kuo-Liang Lee \\ Assistant Professor, Dept. of Marketing \& Distribution Management, Overseas Chinese Institute of Technology, \\ Taichung, Taiwan, R.O.C, lee.kl@ocit.edu.tw \\ Wen-Chih Huang \\ Professor, Dept. of Harbor and River Engineering, National Taiwan Ocean University, Keelung, Taiwan, R.O.C.
}

Follow this and additional works at: https://jmstt.ntou.edu.tw/journal

Part of the Business Commons

\section{Recommended Citation}

Teng, Junn-Yuan; Lee, Kuo-Liang; and Huang, Wen-Chih (2007) "A FUZZY MULTICRITERION Q-ANALYSIS MODEL FOR INTERNATIONAL LOGISTIC-PARK LOCATION SELECTION," Journal of Marine Science and Technology. Vol. 15: Iss. 2, Article 4.

DOI: $10.51400 / 2709-6998.2037$

Available at: https://jmstt.ntou.edu.tw/journal/vol15/iss2/4

This Research Article is brought to you for free and open access by Journal of Marine Science and Technology. It has been accepted for inclusion in Journal of Marine Science and Technology by an authorized editor of Journal of Marine Science and Technology. 


\title{
A FUZZY MULTICRITERION Q-ANALYSIS MODEL FOR INTERNATIONAL LOGISTIC-PARK LOCATION SELECTION
}

\author{
Junn-Yuan Teng*, Kuo-Liang Lee**, and Wen-Chih Huang***
}

Key words: international logistics park, fuzzy MCQA method, grade classification method.

\begin{abstract}
This research empirically evaluates locations for development of international logistics parks from the perspective of Taiwanese firms. A new fuzzy multiple criteria Q-analysis (MCQA) method is proposed to improve the performance judgment of decision-makers. An empirical evaluation of 11 potential locations in northern Taiwan was performed, using local logistics professionals as participants. The fuzzy MCQA method that integrates MCQA, fuzzy measurement and fuzzy grade classification gives an explicit result value for each criterion to be evaluated. The method greatly decreases the complexity of the evaluation process and preserves the advantages of the traditional MCQA method. Finally, the theoretical and practical implications of the research findings are discussed.
\end{abstract}

\section{INTRODUCTION}

In order to develop a logistic park, the government needs to formulate a policy for attracting firms. To ensure smooth business operations, local authorities erect logistics parks in and around ports, special economic regions or re-export zones, intending to enhance both the economic activity and the added value of ports/ airports $[32,26]$.

A logistics park offers logistics service providers the opportunity to establish a warehouse, a container freight station (CFS) and a distribution center (DC), in order to carry out a number of functional activities. The activities include transportation, storage, consolidation, clearance, assembly, inspecting, labeling, packing, marketing, and distribution [21,27]. Local authorities

Paper Submitted 06/05/06, Accepted 09/15/06. Author for Correspondence: Lee, Kuo-Liang. E-mail: lee.kl@ocit.edu.tw.

*Associate Professor, Dept. of Industrial Management, Huafan University, Taipei, Taiwan, R.O.C.

**Assistant Professor, Dept. of Marketing \& Distribution Management, Overseas Chinese Institute of Technology, Taichung, Taiwan, R.O.C.

***Professor, Dept. of Harbor and River Engineering, National Taiwan Ocean University, Keelung, Taiwan, R.O.C. in a variety of locations around the global have developed, or plan to develop, logistics parks to expand the capacity of the existing industry and air/maritime transport infrastructure. In Asia, multifunctional logistics parks have been established at a number of major port cities. The locations include Kaohsiung Yes Logistics Zone (Taiwan), Chiang Kai-shek International airport air logistics park (Taiwan), Busan Logistics Park (Busan), Shanghai Waigaoqiao Bond Logistics Park (Shanghai), Schwartz Logistics hub (Shenzhen), Hong Kong International Distribution center (Hong Kong), and Kepple Distripark (Singapore).

Previous studies have examined determinants affecting firm evaluations of operations such as logistics, distribution, and transshipment centers (park or hub) in particular regions [20, 22, 29, 36]. Research shows that firms often assess several different candidate locations for a particular type of logistic center (park). To our knowledge, however, there have been few empirical studies examining different types of logistics parks among a range of potentially competing locations.

From the standpoint of logistics development, each location offers a unique environment. There is a realization among logistics park planners that the market should be segmented based on customer attribution requirements $[16,19,34]$. It is important that the local government provide appropriate and competitive logistics capabilities and services in and around the logistics park. Given the significant role a logistics park can play in a firm's survival and prosperity, evaluation of logistics parks represent a tremendous challenge for managers of firms operating in global industries [25, 33]. Therefore, preference evaluations of logistics parks are a critical determinant of firm investments.

The preference evaluation of a logistics park is a Multiple Criteria Decision-Making (MCDM) problem. However, the criteria for evaluating logistics parks, as well as the weight assigned to each criterion, differs according to the subject of the evaluation, circumstances, degree of knowledge, and other factors.

The MCQA method, an extended branch of the QAnalysis method, is used to address multiple criteria 
and multiple aspect decision-making problems. QAnalysis dates back to 1974, when mathematician Ron Atkin [2] created this concept based on his research into topology. Atkin and Witten [3] used Q-Analysis to analyze location relationships in chess. Subsequent research has applied MCQA to the study of realityoriented decision-making $[1,7,9,11,12,13,17]$. MCQA is available in variants MCQAI, MCQAII and MCQA III $[14,15]$. MCQA I and MCQA II use Euclidean distance to obtain the gap between practical and ideal alternatives, or the ranking of all alternatives via PRI1 and PRI2 (project rating index), to provide a benchmark for decision-makers.

The evaluative criteria of MCDM problems combine quantitative and qualitative values, and the values for qualitative criteria are often imprecisely defined. Also, their degree of strength changes according to the viewpoint of the evaluator. The desired values and importance weighting of criteria are usually described in linguistic terms: "low", "medium", "high", "very high", and so forth. It is not easy to precisely quantify the rating of each alternative location. The methods described above are thus unable to handle the international logistics park location selection problem.

Fuzzy set theory was developed based on the premise that the key elements in human thinking are not numbers, but linguistic terms or labels of fuzzy sets [4, 37]. Hence, a fuzzy decision-making method under multiple criteria considerations is needed to integrate various linguistic assessment and weights to evaluate the location suitability and determine the best selection [5]. The fuzzy MCQA method, which initiated by Teng [31], was utilized to improve the performance judgment of decision-makers for better availability of MCQA. The method incorporated the performance fuzziness measurement and fuzziness multicriteria grade classification method.

The purpose of this paper is to evaluate the preference relations for different types of logistics parks. An empirical study was conducted in northern Taiwan, using the preferences of local Taiwan firms as the criteria for evaluation. The results of the study provide guidelines for logistics park development. Further, this study proposes a new fuzzy MCQA method that may improve the evaluation performance of decisionmakers.

\section{DEFINITION OF LOGISTICS PARK}

Much research has been performed on operational types for logistics activities. From the viewpoint of systematic development, international distribution systems may make be of the traditional type, the direct exchange type, the transshipment type, or the multina- tional type [23]. Piet et al. [24] classified the logistics chains into three logistics sub-chains, including the production and supply logistic chain, the manufacturing logistic chain, and the distribution logistic chain. Chopra [8] presented six distribution network types in a supply chain. Sheu [27] has proposed six global logistics types that are distinguished by their degree of resource sharing and integration with foreign enterprises. The literature in this area is devoted to particular topics, such as origins and destinations, supply chains, and resource sharing.

Based on the modes international cargo flow: import/export, transshipment, re-import and re-export, functional activities are proposed to define international logistics park types in this research. The distinctive operational features of the four types are displayed in Figure 1.

\section{Type 1: Import-Export (IM/EX type)}

This type of international logistics park moves Origin/Destination (O/D) cargos from the raw \& semifinished product/product supply marketplace ("1") to domestic manufacturing ("2") or consumer ("3") marketplaces. Another moves cargos from the domestic
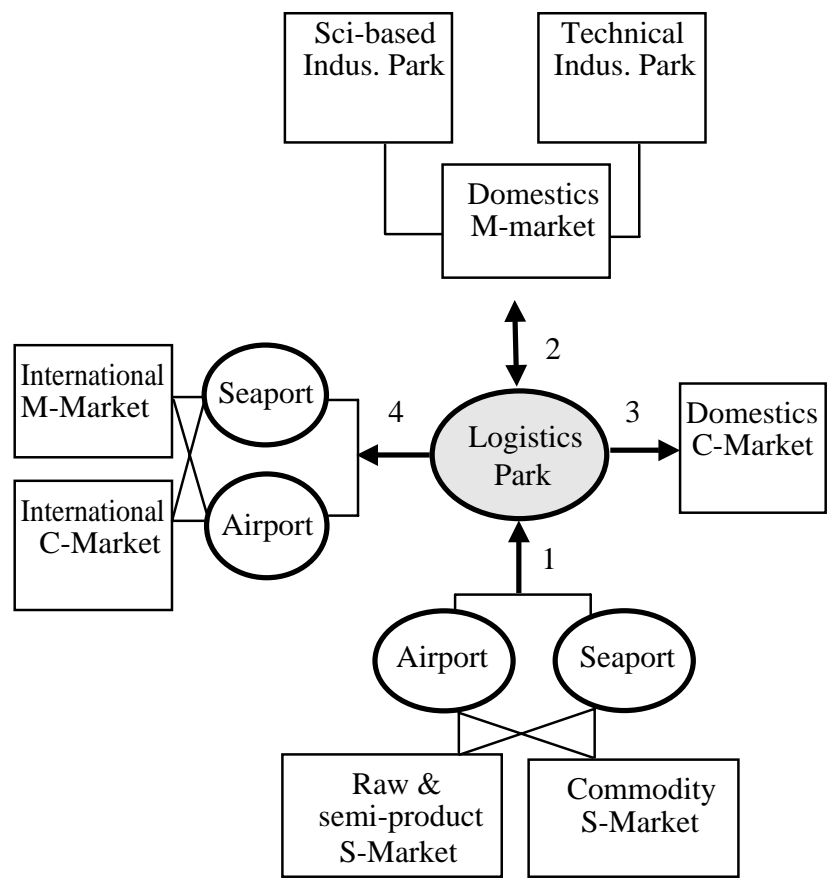

ILP: International Logistics Park S-Market: Supply Market M-Market: Manufacturing Market C-Market: Consumer Market

Fig. 1. Activities of international 
manufacturing ("2") marketplace to the international manufacturing/consumer (" 4 ") marketplace. The type provides the services encompassing transportation within national borders, warehousing, consolidation, and distribution functions. Participating firms might include shipping or airline carriers, freight forwarders, and customs brokers. In this type of logistics park, the port plays a key role in providing the circumstances of the logistics functions. Almost all ports offer these functions.

\section{Type 2: Transshipment type}

This type of international logistics park enables the transshipment of cargoes from marketplace "1" to marketplace "4". It provides services such as transportation, warehousing, consolidation, and distribution, with participants including shipping or airline carriers, freight forwarders, and customs brokers. The port also plays the key role in this type of logistics park, in providing the circumstances of these logistics functions. Only a few ports such as the Kaohsiung Yes Logistics Zone (Taiwan) provide these functions for a particular region.

\section{Type 3: Reprocessing then import type (Re-import type)}

The type supports cargo flow from marketplace "1", importing raw material or semi-finished products, to the domestic consumer marketplace after cargo reprocessing by firms supporting the domestic manufacturing marketplace ("2"). The functions provided include transportation, warehousing, hi-tech reprocessing, consolidation, and distribution functions of participants such as shipping and airline carriers, hi-tech firms, freight forwarders, and custom brokers. In this type of logistics park, hi-tech local manufacturing industries and ports are the key shapers of the circumstances of the logistics functions.

To satisfy the requirement for high quantity commodities, and retain key technologies, foreign access zones (FAZ) were established to develop this type of international logistics park in Japan. Although in the end the policy was not successful due to high reprocessing and distribution costs, the Japanese experiment represents an important case of development of a reimport international logistics park in order to promote production value-added and retain key technologies.

\section{Type 4: Reprocessing then export type (Re-export type)}

This type of international logistics park carries out reprocessing and transshipment of cargos from marketplace " 1 " to marketplace " 4 " after cargo reprocessing by the firms supporting marketplace " 4 ". This type of logistics park offers transportation, warehousing, consolidation, reprocessing, and distribution functions. The functions were provided by the participants of shipping or airline carriers, freight forwarders, hi-tech firms and customs brokers. For this type of park, a hitech industrial environment and port conditions are the key determinants, thus only a handful of locations provide these functions.

In response to the rapid development of global logistics, many locations have transformed the role of transshipment into a re-export service [21]. For example in Taiwan, a large number of foreign multinational corporations (MNCs) order information technology commodities from local Original Equipment Manufacturers (OEM) [10].

Based on their respective logistics activities, there are several key factors for firms in evaluating a logistics park. Such as, the port conditions, transportation convenience, environment and cost conditions, distance between port and logistics park, distance between logistics park and industrial markets, and distance between logistics park and the consumer market. Similarly, the key factors of the four types of logistics parks are transportation convenience, rental cost, natural environment, distance from consumer markets, distance from industrial zones, distance from airports/seaports, and distance from export processing zones. The above criteria were obtained by a survey of 13 logistics executives (seven logistics service providers and six shipping forwarders) and accepted in this research as possessing content validity.

Based on the criteria considered important to firms when making decisions on location selection in logistics parks, the 7 indicators (Table 1) were selected for inclusion in the present study's questionnaire survey. Among the evaluation criteria required to set up the four types of logistics parks, the transportation convenience, rental cost and natural environment are the three most common evaluation criteria, while the other four criteria are particular to specific types of industrial parks.

\section{METHODOLOGY}

Through incorporation of the fuzziness measurement and fuzziness multi-criteria grade classification method of Teng [31], this paper uses the fuzzy MCQA to improve the performance judgment of decision-makers

\section{Fuzzy measurement of location performance}

Assuming $n$ alternatives $A=\left\{A_{i} \mid i=1,2, \ldots, n\right\}$, $(n \geq 1)$ are found under m evaluation criteria $C=\left\{C_{j} \mid\right.$ 
Table 1. Evaluation criteria of four types of logistics parks

\begin{tabular}{lcccc}
\hline Criteria & IM/EX & Re-import & Transship. & Re-export \\
\hline Transportation convenience $\left(C_{1}\right)$ & 0 & & \\
Rental cost $\left(C_{2}\right)$ & & & & \\
Nature environment $\left(C_{3}\right)$ & & & \\
Distance from main consumer market $\left(C_{4}\right)$ & & & \\
Distance from industrial zone $\left(C_{5}\right)$ & & & \\
Distance from airport/seaport $\left(C_{6}\right)$ & & & \\
Distance from export processing zone $\left(C_{7}\right)$ & & & \\
\hline
\end{tabular}

$j=1,2, \ldots, m\},(m \geq 2)$, if the performance value measured by each evaluation criteria is classified into $p$ grades $R=\left\{R_{k} \mid k=1,2, \ldots, p\right\},(p \geq 2)$, grade $R_{i j k}$ represents the subjective judgment of responders viewing $A_{i}$ location under $C_{j}$ criteria, given by the formula below:

$$
R_{i j k}=\left\{R_{k} \mid k=1,2, \ldots, p\right\}, \quad \forall i, j
$$

Where, $R_{i j l}$ represents a higher degree of satisfaction of subjective judgment made by responders viewing $A_{i}$ alternative under $C_{j}$ criteria, $R_{i j 2}$ represents the next higher degree of satisfaction, and $R_{i j p}$ represents dissatisfaction, and so on.

The linguistic variables, such as "very satisfactory", "satisfactory", "ordinarily acceptable", "dissatisfactory" and "rather dissatisfactory", are fuzzy linguistics that can be represented by fuzzy numbers. Formerly, many scholars took the position that "linguistic variables" could be converted into scalar fuzzy numbers, but gave no detailed description of how to determine scalar fuzzy numbers [5]. Satty [26] showed that five scales are a basic judgment method for human beings. Thus, the satisfaction grade of the performance value under various criteria can be classified into several grades such as "very good", "good", "medium", "poor" and "very poor", respectively represented by $R=\left\{R_{1}, R_{2}, R_{3}, R_{4}, R_{5}\right\}$. Meanwhile, the performance values of the grades can be represented by triangular fuzzy numbers, for example, $\widetilde{R}_{k}(k=1,2, \ldots, p)$ showing the fuzzy performance value of $\mathrm{k}$ grade for the alternatives. The fuzzy performance value of $k$ grade is measured as $[0,100]$, the rating interval of $\widetilde{R}_{k}$ is represented by the following formula:

$$
\tilde{R}_{k}=\left(x_{k a}, x_{k b}, x_{k c}\right)
$$

Where, $x_{k a}, x_{k b}, x_{k c}$ are optional values that lie within $[0,100]$ and meet the condition of $x_{k c} \geq x_{k b} \geq x_{k a}$. This fuzzy number shows that, from the perspective of the responder, the performance value of $R_{k}$ grade is between $x_{k a} \sim x_{k c}$, and the crisp performance value is $x_{k b}$. The membership function $u_{\tilde{R}_{k}}(x)$ of fuzzy performance value $\widetilde{R}_{k}$ of $R_{k}$ grade may be expressed by the following formula:

$$
u_{\tilde{R}_{k}}(x)=\left\{\begin{aligned}
0, & x<x_{k a} \\
\frac{x-x_{k a}}{x_{k b}-x_{k a}}, & x_{k a} \leq x<x_{k b} \\
1, & x=x_{k b} \\
\frac{x_{k c}-x}{x_{k c}-x_{k b}}, & x_{k b}<x \leq x_{k c} \\
0, & x>x_{k c}
\end{aligned}\right.
$$

According to the study and analysis of Satty [26], individuals will find it difficult to clearly judge adjacent scales, but will have little trouble distinguishing ratings that are separated by one grade. For example, it is difficult to distinguish the satisfaction grades of "very good" and "good", but easy to distinguish "very good" and "medium". In other words, between adjacent grades there is a fuzzy interval, but not between non-adjacent grades. For this reason, this paper has defined five satisfaction grades of fuzzy performance values as shown in Figure 2.

\section{Fuzzy grade classification method}

Assuming $N$ responders are expressed by $E=\left\{E_{h} \mid\right.$ $h=1,2, \ldots, N\}$, the fuzzy performance values of $A_{i}$ location under $C_{j}$ criteria are represented by $\tilde{r}_{i j}(i=1,2$, $\ldots, n ; j=1,2, \ldots, m)$. Thus, it is possible to measure the percentage of each grade of responders as detailed below:

$$
\begin{aligned}
& \tilde{r}_{i j}=\sum_{k=1}^{p}\left(\frac{N_{i j k}}{N_{i j}}\right) \otimes \tilde{R}_{k}, \forall i, j \\
& N_{i j}=\sum_{k=1}^{p} N_{i j k}, \forall i
\end{aligned}
$$

Where $N_{i j k}$ is the number of responders who judge the 


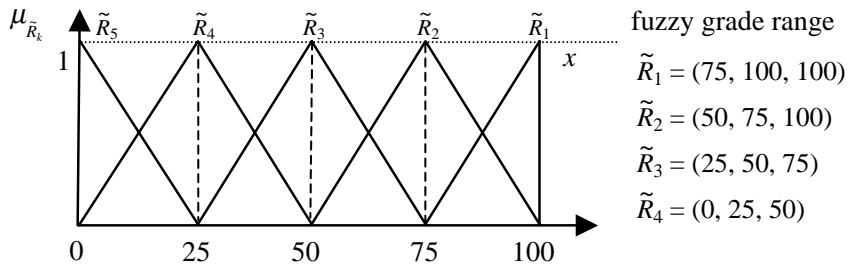

Fig. 2. Grade fuzzy number $\tilde{\boldsymbol{R}}_{k}$.

performance value of $A_{i}$ location as $R_{k}$ grade under $C_{j}$ criteria, and $N_{i j}$ is the total number of responders. In the case in which each responder makes a judgment, $N=N_{i j}$. In a case in which some responders cannot make judgment, $N_{i j}<N, \widetilde{\Sigma}$ indicates fuzzy summation and symbol $\otimes$ indicates fuzzy multiplication. Once the responders have finished the evaluation of alternative locations, the preference structure matrix $\widetilde{P}$ can be obtained below:

$$
\widetilde{P}=\left[\tilde{r}_{i j}\right]_{i \times j}, \quad \forall i, j
$$

As $N_{i j k}$ and $N_{i j}$ are constants, the fuzzy value $\tilde{r}_{i j}$ remains a triangular fuzzy number [18]. Fuzzy numbers $\tilde{r}_{i j}$ and $\widetilde{R}_{k}$ must be compared to determine which grade $\tilde{r}_{i j}$ belongs to. In other words, it is possible to judge based upon the percentage of the area of $\widetilde{R}_{k}$ fuzzy numbers occupied by $\tilde{r}_{i j}$ fuzzy numbers, by obtaining the value $\alpha_{i j k}$ of $R_{k}$ grade as shown in Figure 3. The area of $\tilde{R}_{k}$ occupied by $\tilde{r}_{i j}$ is represented by the oblique shadow. After obtaining the area of oblique shadow (i.e. percentage of triangle $\mathrm{ABC}$ ), it is possible to obtain the grade value $\alpha_{i j k}$, shown by the ratio between two ordinary integrals of membership functions as below:

$$
\alpha_{i j k}=\frac{\int_{y \in D_{k}} u_{\tilde{r}_{i j}}(y) d y}{\int_{x \in D_{k}} u_{\tilde{R}_{k}}(x) d x}, \forall i, j, k
$$

Where, $u_{\widetilde{r}_{i j}}(y)$ is membership function of fuzzy number $\tilde{r}_{i j}$ and $u_{\tilde{R}_{k}}(x)$ is membership function of grade fuzzy number $\widetilde{R}_{k}$ with overlapped fuzzy interval as $D_{k}=\left[x_{k a}\right.$, $\left.y_{c}\right]$.

In order to identify $p$ grades, $(p-1)$ evaluation grade groups comprising every two adjacent grades is created:

$$
\begin{gathered}
R_{1}^{\prime}=\left\{R_{1}, R_{2} \text { or } R_{3} \text { or } \ldots R_{p}\right\} \\
R_{2}^{\prime}=\left\{R_{2}, R_{3} \text { or } R_{4} \text { or } \ldots R_{p}\right\} \\
\vdots \\
R_{p-1}^{\prime}=\left\{R_{p-1}, R_{p}\right\}
\end{gathered}
$$

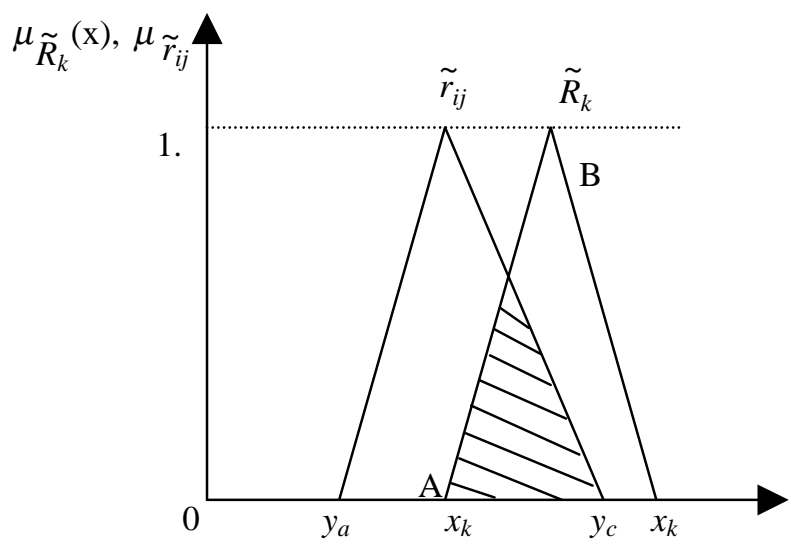

Fig. 3. $R_{k}$ grade attribution.

The fuzzy value $\tilde{r}_{i j}$ may be evaluated according to $R_{1}^{\prime}, R_{2}^{\prime}, \ldots, R_{p-1}^{\prime}$ grades, and the corresponding membership grade $\beta_{1}, \beta_{2}, \ldots, \beta_{p-1}$ can be obtained with the grades classified as per the following rule:

1. $\beta_{1} \geq M$ then $\tilde{r}_{i j} \in R_{1}$; otherwise

2. $\beta_{2} \geq M$ then $\tilde{r}_{i j} \in R_{2}$; otherwise

$(p-1) . \beta_{p-1} \geq M$ then $\tilde{r}_{i j} \in R_{p-1}$;

otherwise $\tilde{r}_{i j} \in R_{p}$

where $\mathrm{M}$ represented the threshold value of membership grade of grade $R_{1}^{\prime}, R_{2}^{\prime}, \ldots, R_{p-1}^{\prime}$

For example, assume there are only two grades $\mathrm{R}=$ $\left\{R_{1}, R_{2}\right\}$. If the membership grade of grade $R_{1}$ reaches the threshold value $M$, the fuzzy value $\tilde{r}_{i j}$ under $c_{j}$ criteria belongs to grade $R_{1}$; otherwise, it belongs to grade $R_{2}$. Generally, the value of $M$ lies between 0.5 or 0.7 . Assuming $\beta_{1}$ and $\beta_{2}$ respectively represent the membership grades of $\tilde{r}_{i j} \in R_{1}$ and $\tilde{r}_{i j} \in R_{2}$, and $\beta_{1}+\beta_{2}$ $=1$, then three cases will be found:

1. $\beta_{1}>M$, then $\tilde{r}_{i j} \in R_{1}$

2. $\beta_{1}=M$, then $\tilde{r}_{i j} \in R_{1}$ or $\tilde{r}_{i j} \in R_{2}$

3. $\beta_{2}>M$, then $\tilde{r}_{i j} \in R_{2}$

When the grade is classified into three variables: $R=\left\{R_{1}, R_{2}, R_{3}\right\}$, the grade classification of fuzzy value $\tilde{r}_{i j}$ may be evaluated as in a two grade classification modes: $R_{1}^{\prime}=\left\{R_{1}, R_{2}\right.$ or $\left.R_{3}\right\}, R_{2}^{\prime}=\left\{R_{2}\right.$ or $\left.R_{3}\right\}$. Meanwhile, it is possible to search the respective membership grade $\left(\beta_{1}, \bar{\beta}_{1}\right),\left(\beta_{2}, \bar{\beta}_{2}\right)$, and $\beta_{1}+\bar{\beta}_{1}=1, \beta_{2}+\bar{\beta}_{2}=1$. Thus, the grade classification can be further developed based upon $\beta_{1}$ and $\beta_{2}$ as detailed below: 
1. $\beta_{1} \geq M$, then $\tilde{r}_{i j} \in R_{1}$

2. $\bar{\beta}_{1} \geq M$, then $\tilde{r}_{i j} \in R_{2}$ or $\tilde{r}_{i j} \in R_{3}$,

depond on $\beta_{2}$

(1) $\beta_{2} \geq M$, then $\tilde{r}_{i j} \in R_{2}$

(2) $\bar{\beta}_{2} \geq M$, then $\tilde{r}_{i j} \in R_{3}$

Under the precondition that the membership grade of $p$ grades summation is 1 according to the grade levels $\left(\alpha_{i j k}\right.$, the membership grade of various grades $\beta_{i j k}(i=1$, $2, \ldots, n ; j=1,2, \ldots, m ; k=1,2, \ldots, p)$ can be obtained from the following formula:

$$
\begin{gathered}
\beta_{i j 1}=\sum_{k=1}^{1} \alpha_{i j k} / \sum_{k=1}^{p} \alpha_{i j k} \\
\beta_{i j 2}=\sum_{k=1}^{2} \alpha_{i j k} / \sum_{k=1}^{p} \alpha_{i j k} \\
\vdots \\
\beta_{i j(p-1)}=\sum_{k=1}^{p-1} \alpha_{i j k} / \sum_{k=1}^{p} \alpha_{i j k} \\
\beta_{i j p}=1
\end{gathered}
$$

\section{Fuzzy weight}

According to the study and analysis of Zadeh [37], the people will find it hard to clearly judge adjacent scales, but easy to distinguish separated ones. For example, it is difficult to distinguish the satisfaction grades of "very good" and "good", but easy to distinguish "very good" and "medium" clearly. In other words, there is a fuzzy interval between adjacent grades other than separated ones. For this reason, the five satisfaction grades of fuzzy performance values were defined shown in Figure 2. In addition, the evaluation scale $[0,100]$ can be converted into $[0,1]$ to facilitate the calculation. As noted earlier, there is a fuzzy interval between adjacent grades, but not between nonadjacent grades. Figure 2 presents the satisfaction grades of fuzzy performance values. The evaluation scale $[0,100]$, can be converted into $[0,1]$ to facilitate calculation.

The importance level of evaluation criterion may be classified into five grades: "absolute importance", "demonstrated importance", "essential importance", "weak importance" and "importance". Collectively, they can be represented by $V=\left\{V_{l} \mid l=1,2, \ldots, 5\right\}$, where, $V_{1}$ indicates "absolute importance", $V_{2}$ "demonstrated importance" and so on. As "absolute importance", "demonstrated importance", "essential importance", "weak importance" and "importance" are still fuzzy linguistics. This paper has adopted triangular fuzzy numbers $\widetilde{W}_{l}(l=1,2, \ldots, 5)$ to represent the scores of five grades, with the corresponding fuzzy numbers shown in Figure 3 , wherein only $\widetilde{R}_{k}$ is converted into $W_{t}$. With the introduction of a $[0,100]$ measurement scale, the fuzzy weight of $l$ grade can be represented by $\tilde{W}_{l}=\left(x_{l a}, x_{l b}, x_{l c}\right)$, of which $x_{l a}, x_{l b}, x_{l c}$ are optional values within $[0,100]$, and meet the condition of $x_{l c} \geq x_{l b} \geq x_{l a}$.

If $N$ logistics professionals judge the importance level of evaluation criteria as grades $V_{l}(l=1,2, \ldots, v)$, represented by $Y_{h j}$ below:

$$
\begin{aligned}
Y_{h j} & =V_{l}, j=1,2, \ldots, m ; h=1,2, \ldots, N ; \\
l & =1,2, \ldots, v
\end{aligned}
$$

The grade judgment matrix of $N$ logistics professionals can be represented by $Y$ :

$$
Y=\left[Y_{h j}\right]_{N \times m}
$$

According to the grade matrix $Y$ of the importance level and majority rule, it is possible to obtain the grade of the consensus weight under each evaluation criteria. Take $Z\left[V_{l}\right]_{j}$ as the number of $N$ logistics professionals who judge the importance under $C_{j}$ criteria as grade $V_{l}$, and take $Z\left[\Sigma V_{l}\right]_{j}$ as the number of professionals with their judgment grade $V_{l}$ summated to grade $V_{l}$, namely:

$$
Z\left[\sum V_{l}\right]_{j}=\sum_{g=l}^{v} Z\left[V_{g}\right]_{j}, \forall j, l=1,2, \ldots, v
$$

If the importance level of consensus judgment under $C_{j}$ evaluation criteria is judged as grade $V_{1}$, it shows that the importance level under $C_{j}$ evaluation criteria meets grades from $V_{2}$ to $V_{v}$. Namely, the grade $V_{1}$ includes grades $V_{2} \sim V_{v}$. If the importance level of common understanding under $C_{j}$ evaluation criteria is judged as grade $V_{2}$, it shows that the importance level under $C_{j}$ evaluation criteria meets the grades from $V_{3}$ to $V_{v}$ apart from grade $V_{1}$. Namely, the grade $V_{2}$ implies grades $V_{3} \sim V_{v}$ apart from grade $V_{1}$. According to the majority rule, $Z\left[\Sigma V_{l}\right]_{j}$ must exceed a certain majority value $M$, namely

$$
Z\left[\Sigma V_{l}\right]_{j} \geq M
$$

Where the $M$ value can be jointly agreed upon by $N$ logistics professionals. The $M$ value can be determined by the following formula with the introduction of the majority rule [32]:

$$
M= \begin{cases}(N / 2)+1 & N \text { is even number } \\ {[(N-1) / 2]+1} & N \text { is odd number }\end{cases}
$$


The majority rule can also incorporate numbers exceeding two-thirds or three-fourths, depending upon the level of consensus. Based on the analysis of majority rule, it is possible to obtain grade $V_{u}$ of consensus for the importance level of $C_{j}$ criteria, and convert it into the fuzzy weight under the criteria $\widetilde{W}_{j}$ :

$$
\tilde{W}_{j}=V_{u}, V_{u} \in V, u=1,2, \ldots, v
$$

\section{Fuzzy MCQA model}

In the case of grade $R_{k}$, grade $R_{i j k}$ within preference structure matrix $\tilde{P R}$ may be represented by 1 , otherwise, it is represented by 0 . Therefore, the preference structure matrix within formula (10) can be converted into the following $p$ 0-1 type incidence matrix $B_{R_{k}}(k=1,2$, $\ldots, p)$ :

$$
\begin{gathered}
B_{R_{k}}=\left[b_{i j}\right]_{i \times j} \quad \forall i, j, k \\
b_{i j}=\left\{\begin{array}{l}
0, \text { if } \tilde{R}_{i j k}<\tilde{R}_{k} \\
1, \text { if } \tilde{R}_{i j k} \geq \tilde{R}_{k}
\end{array}\right.
\end{gathered}
$$

Based on the incidence matrix of each grade, it is possible to obtain and meet the criteria number matrix of this grade via $q$-connectivity, by obtaining the following $q$-connectivity matrix $S^{R_{k}}(k=1,2, \ldots, p)$ :

$$
S^{R_{k}}=B_{R_{k}}\left[B_{R_{k}}\right]^{T}-e^{T} e
$$

Where

$S^{R_{k}}$ : unde $R_{k}$ grade $q$-connectivity matrix

$\left[B_{R_{k}}\right]^{T}:$ the transfermatrix of incidence matrix

According to the $q$-connectivity matrix obtained using the formula above, it is possible to obtain the fuzzy project satisfaction index $\widetilde{P S_{i}}$ and fuzzy project comparison index $\tilde{P C_{i}}$ for various locations, each of which is defined below:

$$
\begin{aligned}
& \tilde{P S}_{i}=\tilde{\sum}_{k} \tilde{R}_{k} \otimes \tilde{T}_{i k}, \forall i \\
& \tilde{T}_{i k}=\tilde{\sum}_{j} b_{i j}^{k} \otimes \tilde{w}_{j}, \forall i, k \\
& \tilde{P C_{i}}=\sum_{k} \tilde{R}_{k}\left[\hat{q}_{i R_{k}}-q_{i R_{k}}^{*}\right], \forall i \\
& q_{i R_{k}}^{*}=\underset{\substack{\operatorname{maximum}^{\prime}=1,2, \ldots, n \\
i \neq i^{\prime}}}{\max _{k}\left(i, i^{\prime}\right)}
\end{aligned}
$$

$$
\hat{q}_{i R_{k}}=S^{R_{k}}(i, i)
$$

where

$b_{i j}^{k}=$ the 0-1 type incidence value of $\mathrm{k}$ grade (Eq. 16) grade $R_{i j k}$ within preference structure matrix $\tilde{P R}$ can be represented by 1 ; otherwise, it represented by 0 .

$\tilde{T}_{i k}=$ the incidence weight of grade $R_{k}$ in $i$ location. $\hat{q}_{i R_{k}}=S^{R_{k}}(i, i)$ is represented by the dimension of $A_{i}$ alternative under grade $R_{k}$ and

$$
q_{i R_{k}}^{*}=\underset{\substack{i^{\prime}=1,2, \ldots, n \\ i \neq i}}{\operatorname{maximum}} S^{R_{k}}\left(i, i^{\prime}\right) \text { is presented by the }
$$

maximum dimension of all alternatives under grade $R_{k}$.

The fuzzy project satisfaction index indicates the comprehensive satisfaction of logistics professionals with $A_{i}$. The greater the number, the higher the performance is. As fuzzy project satisfaction index is only able to measure the absolute satisfaction of various alternatives, rather than the relative satisfaction, the fuzzy comparison index must be obtained in order to compare alternatives. However, pairwise comparison method will complicate the calculation. In an effort to simplify the mathematical operation, it is often assumed that preference transtivity will occur [28]. With a view to the fuzzy MCQA method in this paper, it is also assumed that the preference transtivity will take place. Therefore, when obtaining the value of $\tilde{P C_{i}}$, it is only necessary to determine the maximum $q_{i R_{k}}^{*}$ for comparison with $q_{i R_{k}}^{*}$, thus enabling us to dispense with consideration of complex pairwise comparison method.

As both $\tilde{P S}_{i}$ and $\tilde{P C_{i}}$ are fuzzy numbers. Hence, it would be unusual to compare them directly to crisp values. A defuzzier is thus required. Based upon the ranking method of fuzzy numbers for Kim-Park modified by Teng and Tzeng [30], this paper will convert the fuzzy numbers of $\tilde{P S_{i}}$ and $\tilde{P C_{i}}$ into real numbers. Take $\tilde{P H_{i}}$ as the general expression of $\tilde{P S_{i}}$ and $\tilde{P C_{i}}$ as shown below:

$$
\tilde{P H_{i}}=\left(L H_{i}, M H_{i}, R H_{i}\right), i=1,2, \ldots, n
$$

The greater the interval of $M H_{i}, R H_{i}$ higher the positive assessment of location $A_{i}$, while the greater the interval of $L H_{i}, M H_{i}$ the greater the negative assessment of location $A_{i}$. Take $\mathrm{S}$ as the range of all alternatives $\widetilde{P H_{i}}$, the measurement values as well as an universe of discourse, of which $s$ is an element of set $S$ showing an optional value within the range of $S$. Take $\alpha_{i}$ as a value between $[0,1]$, showing a positive expert assessment of 
the alternatives, whereas $\left(1-\alpha_{i}\right)$ shows a negative assessment of the alternatives. If $u_{0}\left(\tilde{P H_{i}}\right)$ represents a positive membership grade of the fuzzy satisfaction index in $A_{i}$, and $u_{p}\left(\widetilde{P H_{i}}\right)$ represents a negative membership grade, then the value of $u_{T}\left(\widetilde{P H_{i}}\right)$ may be obtained by the following formula.

$$
\begin{aligned}
& \mu_{T}\left(\tilde{P H}_{i}\right)=\alpha_{i} \mu_{0}\left(\tilde{P H}_{i}\right)+\left(1-\alpha_{i}\right) \mu_{p}\left(\tilde{P H_{i}}\right), \\
& i=1,2, \ldots, n \\
& \alpha_{i}=\left(R H_{i}-M H_{i}\right) /\left(R H_{i}-L H_{i}\right), \forall i \\
& \mu_{0}\left(\tilde{P H}_{i}\right)=\left(S_{2_{i}}-S_{\min }\right) /\left(S_{\max }-S_{\min }\right), \forall i \\
& \mu_{p}\left(\tilde{P H}_{i}\right)=1-\left[\left(S_{\max }-S_{2_{i}}\right) /\left(S_{\max }-S_{\min }\right), \forall i\right. \\
& s_{1_{i}}=\frac{s_{\max } R H_{i}-s_{\min } M H_{i}}{\left(R H_{i}-M H_{i}\right)+\left(s_{\max }-s_{\min }\right)} \\
& s_{2_{i}}=\frac{s_{\max } M H_{i}-s_{\min } L H_{i}}{\left(M H_{i}-L H_{i}\right)+\left(s_{\max }-s_{\min }\right)} \\
& s_{\max }=\operatorname{sup~S} \\
& s_{\min }=\inf S \\
& \mathrm{~S}=\bigcup_{i \in A} \tilde{P H_{i}}
\end{aligned}
$$

where $s_{1}$ is an element of set $S$ showing an optional value within the range of $M H_{i}, R H_{i}$, and $s_{2_{i}}$ is an element of set $S$ showing an optional value within the range of $L H_{i}, M H_{i}$.

The fuzzy MCQA model in this paper obtains the evaluation ranking of alternatives based upon the defuzzier value of $\widetilde{P S_{i}}$ and $\tilde{P C_{i}}$. The location $A_{i}$ project rating index $P R I_{i}$, may be obtained by the following formula:

$$
P R I_{i}=\left[\left(1-u_{T}\left(\tilde{P S}_{i}\right)\right)^{r}+\left(1-u_{T}\left(\tilde{P C}_{i}\right)\right)^{r}\right]^{1 / r}, \forall i
$$

The smaller the $P R I_{i}$ value is, the closer the distance between the vector of a particular alternative and the ideal vector -- the better the alternative is. Conversely, the higher the value of $P R I_{i}$, the worse the alternative is. The concept of Euclidean distance is applied to formula (33), where the $r$ value is often found to be 2 .

\section{EMPIRICAL STUDY}

In this section, we evaluate locations for developing international logistics parks in north of Taiwan. The locations include Keelung Port $\left(A_{1}\right)$, Loudo Industrial Zone $\left(A_{2}\right)$, CFS of Wudo and Shihjr $\left(A_{3}\right)$, the area adjacent to Nanken Junction $\left(A_{4}\right)$, CKS International Airport $\left(A_{5}\right)$, Taoyuan Industrial Zone $\left(A_{6}\right)$, the area adjacent to Taoyuan Industrial Zone $\left(A_{7}\right)$, Hsinchu Science-Based Industrial Park $\left(A_{8}\right)$, the area adjacent to Hsinchu Science-Based Industrial Park $\left(A_{9}\right)$, Taipei Port $\left(A_{10}\right)$ and the special zone of Taipei Port $\left(A_{11}\right)$. The 11 candidate locations were evaluated by comparing respondent satisfaction with ability of each location to meet each investment criteria.

\section{Evaluation structure and procedure}

The hierarchical structure of the criteria for evaluating locations for development of logistics parks was constructed as shown in Figure 4. Eleven candidate locations were chosen for location analysis, labeled $A_{1} \sim A_{11}$, respectively. Similarly, the hierarchical structure of the evaluation evaluation criteria for firms selecting the location of four different types of logistics parks was constructed as shown in Figure 4. These criteria include: transportation convenience $\left(C_{1}\right)$, rental cost $\left(C_{2}\right)$, natural environment $\left(C_{3}\right)$, distance from main consumer market $\left(C_{4}\right)$, distance from industrial zone $\left(C_{5}\right)$, distance from airport/seaport $\left(C_{6}\right)$, and distance from export processing zone $\left(C_{7}\right)$.

This evaluation method was used in the empirical study in collaboration with fuzzy measurement, fuzzy grade classification, fuzzy weight and the MCQA method. As with the evaluation criteria under research and discussion, it is intended to collect the actual quantification and qualification performance value of various locations in order to facilitate location decisionmaking in development of international logistics parks. However, owing to different levels of satisfaction displayed by logistics professionals toward the actual performance value, this paper measures their satisfaction via the fuzzy measurement method, and then classifies the grade of the performance value via a fuzzy grade classification method. To assess the importance level of the evaluation criteria, this paper obtains the fuzzy weight using majority rule. Based upon the fuzzy grade and fuzzy weight as well as the MCQA method, the fuzzy project satisfaction index and fuzzy project comparison index of the various locations were obtained. Finally, a defuzzier was applied via fuzzy ranking method to obtain the Project Rating Index (PRI) of the various locations. The framework of decision-making for international logistics park location is shown in Figure 5.

\section{Target sample collection}

To assess the preference relations of international 


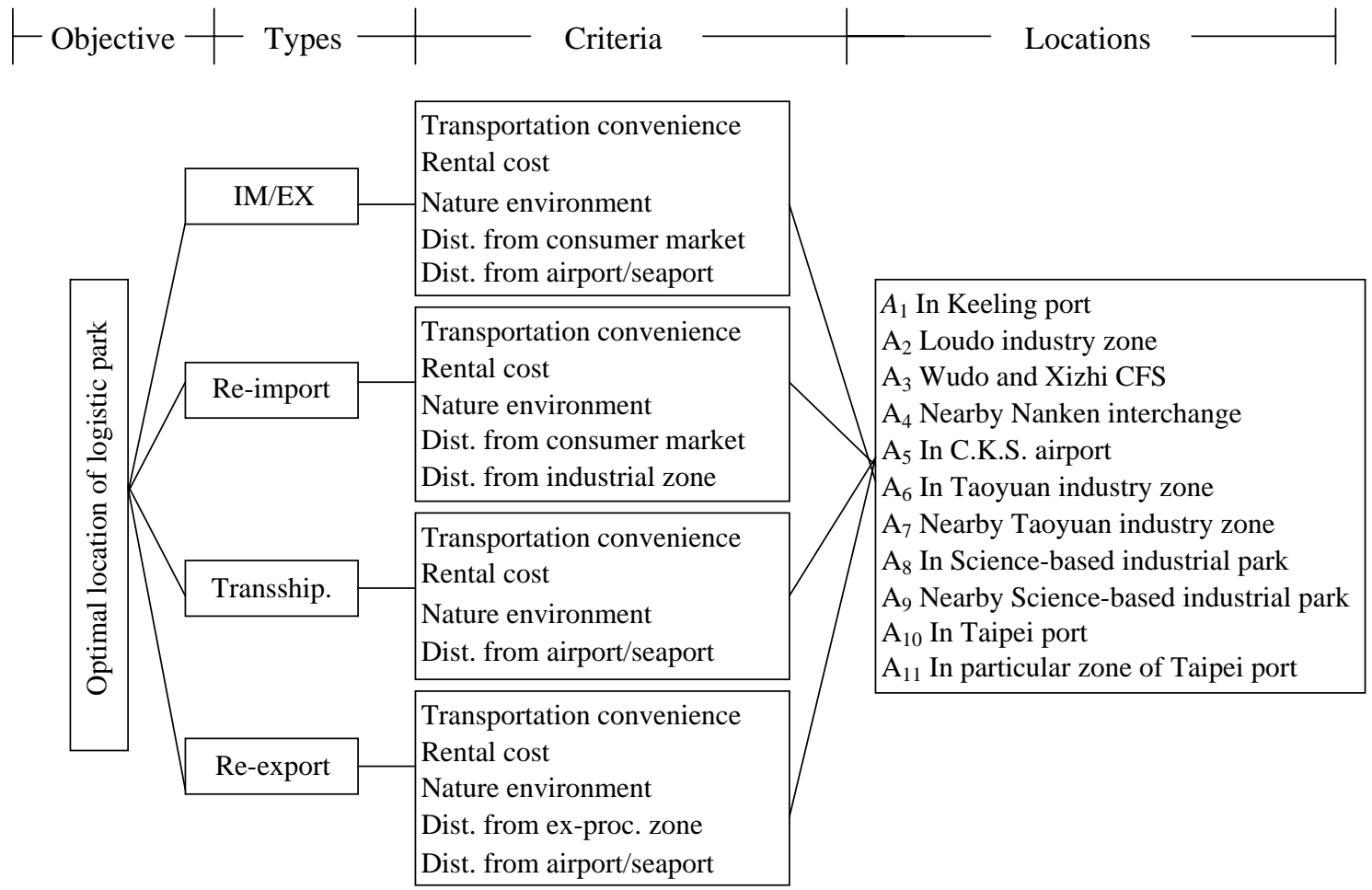

Fig. 4. Multicriteria evaluative system of logistics park.

logistics park, we developed a structured questionnaire based on the seven stages outlined by Churchill [6], whose approach defines a solid foundation for the construction of questionnaires. The content validity of the questionnaire used in this study was tested through interviews with practitioners, and questions were based on previous studies and discussions with 13 logistics professionals located in northern Taiwan. Discussions resulted in minor modifications to the wording and examples provided in some measurement items, which were finally accepted as relevant and possessing content validity. The refined measurement items were included in the final survey questionnaire.

The sampled firms operate in a variety of industries, including logistics. Due to limitations of finance and time, the questionnaire survey was sent to the managers of shipping companies (30), freight forwarders (40), and the membership of the Taiwan International Logistics Association (40). The revised questionnaire was sent to a manager in each of our target sample firms by mail, email or interview. The total number of usable responses was 29. The overall response rate for this study was therefore 24.1 per cent. Responses comprised shipping companies ( 7 firms, $24.1 \%$ ), freight forwarders (12 firms, 41.4\%) and members of the Taiwan International Association (10 firms, 34.5\%).

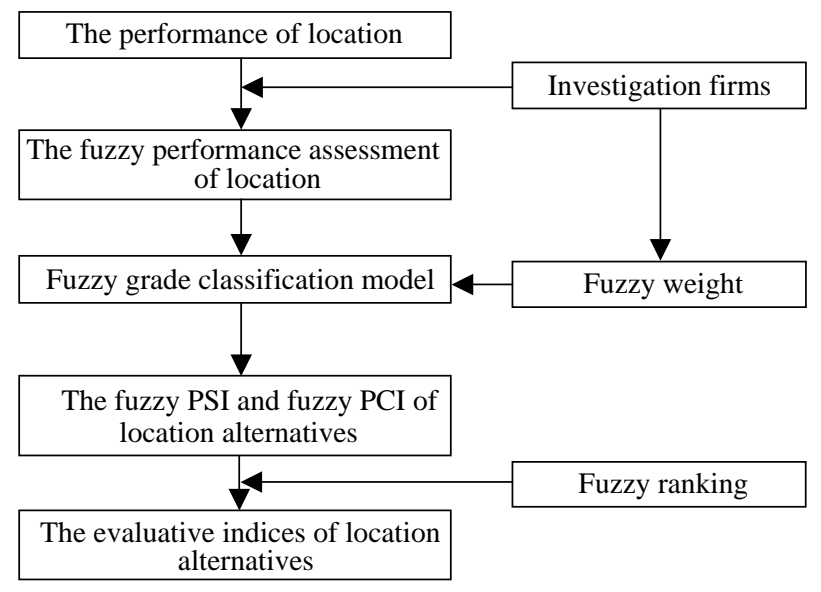

Fig. 5. Location decision model of international logistics park.

\section{Analysis and results}

For the evaluation criteria of four types of logistics parks, the satisfaction grade of potential locations can be classified into "very good $\left(R_{1}\right)$ ", " $\operatorname{good}\left(R_{2}\right)$ ", "me$\operatorname{dium}\left(R_{3}\right)$ ", "poor $\left(R_{4}\right)$ " and "very poor $\left(R_{5}\right)$ ". Logistics professionals tend to estimate the performance value and judge the satisfaction grade from one evaluation 
criterion particular to a suitable candidate location. The differing preferences of the logistics professionals were assessed using the fuzzy measurement method, while the fuzzy grade classification method obtained the grade of potential locations under each evaluation criteria. Detailed results are displayed in Table 2.

In terms of the weight of criteria, this paper has classified the importance level of the evaluation criteria into five grades: "absolute importance $\left(V_{1}\right)$ )","demonstrated importance $\left(V_{2}\right)$ ", "essential importance $\left(V_{3}\right)$ ", "weak importance $\left(V_{4}\right)$ " and "importance $\left(V_{5}\right)$ ". The logistics professionals tend to judge the grade based on the importance of each evaluation criteria, leading to differing judgments. Thus, this paper obtains the fuzzy weight for a common grade via majority rule (Table 3 ).

Consideration of the results listed in Table 2 and Table 3, as well as the evaluation criteria of the four types of logistics parks. It is possible to analyze and

Table 2. The classification contribution of candidate location at each criterion

\begin{tabular}{cccccccc}
\hline Location & $C_{1}$ & $C_{2}$ & $C_{3}$ & $C_{4}$ & $C_{5}$ & $C_{6}$ & $C_{7}$ \\
\hline$A_{1}$ & $R_{2}$ & $R_{3}$ & $R_{3}$ & $R_{2}$ & $R_{2}$ & $R_{1}$ & $R_{4}$ \\
$A_{2}$ & $R_{3}$ & $R_{2}$ & $R_{3}$ & $R_{3}$ & $R_{3}$ & $R_{2}$ & $R_{4}$ \\
$A_{3}$ & $R_{3}$ & $R_{2}$ & $R_{2}$ & $R_{2}$ & $R_{3}$ & $R_{2}$ & $R_{3}$ \\
$A_{4}$ & $R_{2}$ & $R_{3}$ & $R_{3}$ & $R_{2}$ & $R_{2}$ & $R_{2}$ & $R_{3}$ \\
$A_{5}$ & $R_{2}$ & $R_{4}$ & $R_{2}$ & $R_{3}$ & $R_{2}$ & $R_{1}$ & $R_{3}$ \\
$A_{6}$ & $R_{2}$ & $R_{3}$ & $R_{3}$ & $R_{3}$ & $R_{3}$ & $R_{3}$ & $R_{2}$ \\
$A_{7}$ & $R_{3}$ & $R_{3}$ & $R_{3}$ & $R_{3}$ & $R_{3}$ & $R_{4}$ & $R_{2}$ \\
$A_{8}$ & $R_{2}$ & $R_{4}$ & $R_{3}$ & $R_{3}$ & $R_{3}$ & $R_{4}$ & $R_{2}$ \\
$A_{9}$ & $R_{3}$ & $R_{2}$ & $R_{3}$ & $R_{3}$ & $R_{3}$ & $R_{3}$ & $R_{2}$ \\
$A_{10}$ & $R_{3}$ & $R_{3}$ & $R_{3}$ & $R_{2}$ & $R_{2}$ & $R_{2}$ & $R_{4}$ \\
$A_{11}$ & $R_{3}$ & $R_{3}$ & $R_{3}$ & $R_{3}$ & $R_{2}$ & $R_{2}$ & $R_{3}$ \\
\hline
\end{tabular}

obtain the fuzzy project satisfaction index $\left(\tilde{P S_{i}}\right)$, fuzzy project comparison index $\left(\tilde{P C_{i}}\right)$, and corresponding crisp values $\left(\mu_{T}\left(\tilde{P S_{i}}\right),\left(\mu_{T}\left(\tilde{P C_{i}}\right)\right.\right.$ via fuzzy MCQA method (Tables $4,5,6$, and 7 ) for each of the four groups. Then, the project rating index $(P R I)$ of the potential locations can be obtained from formula (33) based on the crisp value of $\widetilde{P S_{i}}$ and $\tilde{P C_{i}}$. Given the same importance of the four types of logistics parks, it is possible to calculate the gross project rating index of potential locations. The lower the value of the gross project rating index, the better the evaluation of the location choice. Therefore, the order of priority of the potential international logistics park locations can be obtained (Table 8). Table 8 shows satisfaction grade of 36 logistics professionals toward each of the 11 potential locations for an international logistics park. The top three are the CFS of Wudo and Shihjr $\left(A_{3}\right)$, CKS International Airport $\left(A_{5}\right)$ and Keelung Port $\left(A_{1}\right)$.

\section{Discussion}

In the case of most importance for a single type of logistics park, it is assumed that the importance weight of the most important logistics park is $0.5,0.6,0.7$ and 0.8 , while the other three logistics parks share the

Table 3. The consensus grade and fuzzy weight of criteria $C_{j}$

\begin{tabular}{cccccc}
\hline Criteria & $\begin{array}{c}\text { Consensus } \\
\text { grade }\end{array}$ & $\begin{array}{c}\text { Fuzzy } \\
\text { weight }\end{array}$ & Criteria & $\begin{array}{c}\text { Consensus } \\
\text { grade }\end{array}$ & $\begin{array}{c}\text { Fuzzy } \\
\text { weight }\end{array}$ \\
\hline$C_{1}$ & $V_{1}$ & $(0.75,1.0,1.0)$ & $C_{5}$ & $V_{2}$ & $(0.5,0.75,1.0)$ \\
$C_{2}$ & $V_{2}$ & $(0.5,0.75,1.0)$ & $C_{6}$ & $V_{2}$ & $(0.5,0.75,1.0)$ \\
$C_{3}$ & $V_{3}$ & $(0.25,0.5,0.75)$ & $C_{7}$ & $V_{2}$ & $(0.5,0.75,1.0)$ \\
$C_{4}$ & $V_{2}$ & $(0.5,0.75,1.0)$ & & & \\
\hline
\end{tabular}

Table 4. PSI and PCI value of import/export type international logistics park

\begin{tabular}{ccccc}
\hline Location $\left(A_{i}\right)$ & $\tilde{P S_{i}}$ & $\mu_{T}\left(\tilde{P S}_{i}\right)$ & $\tilde{P C_{i}}$ & $\mu_{T}\left(\tilde{P C}_{i}\right)$ \\
\hline$A_{1}$ & $(1.88,2.75,3.44)$ & 0.69 & $(0.00,0.00,0.00)$ & 0.00 \\
$A_{2}$ & $(1.13,1.69,2.19)$ & 0.41 & $(0.00,0.00,0.00)$ & 0.00 \\
$A_{3}$ & $(1.50,2.31,3.06)$ & 0.58 & $(1.00,1.50,2.00)$ & 0.70 \\
$A_{4}$ & $(1.50,2.19,2.69)$ & 0.54 & $(0.00,0.00,0.00)$ & 0.00 \\
$A_{5}$ & $(1.63,2.44,3.06)$ & 0.60 & $(0.50,0.75,1.00)$ & 0.39 \\
$A_{6}$ & $(1.00,1.44,1.69)$ & 0.31 & $(0.00,0.00,0.00)$ & 0.00 \\
$A_{7}$ & $(0.50,0.75,0.94)$ & 0.10 & $(0.00,0.00,0.00)$ & 0.00 \\
$A_{8}$ & $(0.75,1.06,1.19)$ & 0.19 & $(0.00,0.00,0.00)$ & 0.00 \\
$A_{9}$ & $(0.88,1.31,1.69)$ & 0.30 & $(0.00,0.00,0.00)$ & 0.00 \\
$A_{10}$ & $(1.13,1.69,2.19)$ & 0.41 & $(0.00,0.00,0.00)$ & 0.00 \\
$A_{11}$ & $(0.88,1.31,1.69)$ & 0.30 & $(0.00,0.00,0.00)$ & 0.00 \\
\hline
\end{tabular}

Note: PSI: Project Satisfaction Index; PCI: Project Comparison Index 
remaining weight (calculated by weight summation 1). A ranking of the priority of the 11 international logistics park locations may thus be obtained. The optimum location is CFS of Wudo and $\operatorname{Shihjr}\left(A_{3}\right)$, or CKS Inter- national Airport $\left(A_{5}\right)$ when the importance weight of a transshipment mode logistics park is 0.7 or 0.8 (Table 9).

A sensitivity analysis was undertaken to clarify

Table 5. PSI and PCI value of re-import type international logistics park

\begin{tabular}{ccccc}
\hline Location $\left(A_{i}\right)$ & $\tilde{P S_{i}}$ & $\mu_{T}\left(\tilde{P S}_{i}\right)$ & $\tilde{P C}_{i}$ & $\mu_{T}\left(\tilde{P C_{i}}\right)$ \\
\hline$A_{1}$ & $(1.50,2.19,2.69)$ & 0.67 & $(0.00,0.00,0.00)$ & 0.00 \\
$A_{2}$ & $(0.88,1.31,1.69)$ & 0.35 & $(0.00,0.00,0.00)$ & 0.00 \\
$A_{3}$ & $(1.25,1.94,2.56)$ & 0.59 & $(1.00,1.50,2.00)$ & 0.70 \\
$A_{4}$ & $(1.50,2.19,2.69)$ & 0.67 & $(0.00,0.00,0.00)$ & 0.00 \\
$A_{5}$ & $(1.25,1.88,2.31)$ & 0.55 & $(0.50,0.75,1.00)$ & 0.39 \\
$A_{6}$ & $(1.00,1.44,1.69)$ & 0.37 & $(0.00,0.00,0.00)$ & 0.00 \\
$A_{7}$ & $(0.63,0.94,1.19)$ & 0.18 & $(0.00,0.00,0.00)$ & 0.00 \\
$A_{8}$ & $(0.88,1.25,1.44)$ & 0.29 & $(0.00,0.00,0.00)$ & 0.00 \\
$A_{9}$ & $(0.88,1.31,1.69)$ & 0.35 & $(0.50,0.75,1.00)$ & 0.00 \\
$A_{10}$ & $(1.13,1.69,2.19)$ & 0.50 & $(0.50,0.75,1.00)$ & 0.39 \\
$A_{11}$ & $(0.88,1.31,1.69)$ & 0.35 & & 0.39 \\
\hline
\end{tabular}

Note: PSI: Project Satisfaction Index; PCI: Project Comparison Index

Table 6. PSI and PCI value of transshipment type international logistics park

\begin{tabular}{ccccc}
\hline Location $\left(A_{i}\right)$ & $\tilde{P S_{i}}$ & $\mu_{T}\left(\tilde{P S}_{i}\right)$ & $\tilde{P C}_{i}$ & $\mu_{T}\left(\tilde{P C_{i}}\right)$ \\
\hline$A_{1}$ & $(1.50,2.19,2.69)$ & 0.67 & $(0.00,0.00,0.00)$ & 0.00 \\
$A_{2}$ & $(1.00,1.50,1.94)$ & 0.46 & $(0.00,0.00,0.00)$ & 0.00 \\
$A_{3}$ & $(1.13,1.75,2.31)$ & 0.54 & $(0.50,0.75,1.00)$ & 0.70 \\
$A_{4}$ & $(1.13,1.75,2.31)$ & 0.48 & $(0.00,0.00,0.00)$ & 0.00 \\
$A_{5}$ & $(1.50,2.25,2.81)$ & 0.68 & $(0.50,0.75,1.00)$ & 0.70 \\
$A_{6}$ & $(0.88,1.25,1.44)$ & 0.34 & $(0.00,0.00,0.00)$ & 0.00 \\
$A_{7}$ & $(0.38,0.56,0.69)$ & 0.09 & $(0.00,0.00,0.00)$ & $0.00)$ \\
$A_{8}$ & $(0.63,0.99,0.94)$ & 0.19 & $(0.00,0.00,0.00)$ & 0.00 \\
$A_{9}$ & $(0.75,1.13,1.44)$ & 0.32 & $(0.00,0.00,0.00)$ & 0.00 \\
$A_{10}$ & $(0.75,1.13,1.44)$ & 0.32 & $(0.00,0.00,0.00)$ & 0.00 \\
$A_{11}$ & $(0.75,1.13,1.44)$ & 0.32 & & 0.00 \\
\hline
\end{tabular}

Note: PSI: Project Satisfaction Index; PCI: Project Comparison Index

Table 7. PSI and PCI value of re-export type international logistics park

\begin{tabular}{ccccc}
\hline Location $\left(A_{i}\right)$ & $\tilde{P S_{i}}$ & $\mu_{T}\left(\tilde{P S_{i}}\right)$ & $\tilde{P C_{i}}$ & $\mu_{T}\left(\tilde{P C_{i}}\right)$ \\
\hline$A_{1}$ & $(0.75,1.06,1.19)$ & 0.40 & $(0.00,0.00,0.00)$ & 0.00 \\
$A_{2}$ & $(0.63,0.94,1.19)$ & 0.37 & $(0.00,0.00,0.00)$ & 0.00 \\
$A_{3}$ & $(0.88,1.38,1.81)$ & 0.59 & $(0.50,0.75,1.00)$ & 0.70 \\
$A_{4}$ & $(0.88,1.25,1.44)$ & 0.50 & $(0.00,0.00,0.00)$ & 0.00 \\
$A_{5}$ & $(0.88,1.31,1.56)$ & 0.54 & $(0.50,0.75,1.00)$ & 0.70 \\
$A_{6}$ & $(1.13,1.63,1.94)$ & 0.69 & $(0.00,0.00,0.00)$ & 0.00 \\
$A_{7}$ & $(0.75,1.13,1.44)$ & 0.47 & $(0.00,0.00,0.00)$ & $0.00)$ \\
$A_{8}$ & $(1.00,1.44,1.69)$ & 0.60 & $(0.00,0.00,0.00)$ & 0.00 \\
$A_{9}$ & $(0.75,1.13,1.44)$ & 0.47 & $(0.00,0.00,0.00)$ & 0.00 \\
$A_{10}$ & $(0.38,0.56,0.69)$ & 0.14 & $(0.00,0.00,0.00)$ & 0.00 \\
$A_{11}$ & $(0.50,0.75,0.94)$ & 0.26 & 0.00 \\
\hline
\end{tabular}

Note: PSI: Project Satisfaction Index; PCI: Project Comparison Index 
Table 8. Ranking order for location developing logistics park in northern Taiwan area

\begin{tabular}{|c|c|c|c|c|c|c|}
\hline \multirow{2}{*}{ Location $\left(A_{i}\right)$} & IM/EX & Re-import & Transship. & Re-export & \multirow{2}{*}{$T P R I_{i}$} & \multirow{2}{*}{ Order } \\
\hline & $P R I_{j}$ & $P R I_{i}$ & $P R I_{i}$ & $P R I_{i}$ & & \\
\hline$A_{1}$ & 1.05 & 1.05 & 1.05 & 1.17 & 4.32 & 3 \\
\hline$A_{2}$ & 1.16 & 1.19 & 1.14 & 1.18 & 4.67 & 8 \\
\hline$A_{3}$ & 0.51 & 0.51 & 0.55 & 0.50 & 2.07 & 1 \\
\hline$A_{4}$ & 1.10 & 1.05 & 1.13 & 1.12 & 4.40 & 4 \\
\hline$A_{5}$ & 0.73 & 0.76 & 0.44 & 0.55 & 2.48 & 2 \\
\hline$A_{6}$ & 1.21 & 1.18 & 1.20 & 1.05 & 4.64 & 7 \\
\hline$A_{7}$ & 1.34 & 1.29 & 1.35 & 1.13 & 5.11 & 11 \\
\hline$A_{8}$ & 1.29 & 1.23 & 1.28 & 1.08 & 4.88 & 10 \\
\hline$A_{9}$ & 1.22 & 1.19 & 1.21 & 1.13 & 4.75 & 9 \\
\hline$A_{10}$ & 1.16 & 0.79 & 1.21 & 1.32 & 4.48 & 5 \\
\hline$A_{11}$ & 1.22 & 0.89 & 1.21 & 1.25 & 4.57 & 6 \\
\hline
\end{tabular}

Table 9. Location ranking order with single type of logistics park

\begin{tabular}{|c|c|c|c|c|c|c|c|c|c|c|c|c|c|c|c|c|}
\hline \multirow{3}{*}{ Location } & \multicolumn{15}{|c|}{ Types } & \\
\hline & \multicolumn{4}{|c|}{ IM/EX } & \multicolumn{4}{|c|}{ Re-import } & \multicolumn{4}{|c|}{ Transship. } & \multicolumn{4}{|c|}{ Re-export } \\
\hline & $0.5^{*}$ & $0.6^{*}$ & $0.7^{*}$ & $0.8^{*}$ & $0.5^{*}$ & $0.6^{*}$ & $0.7^{*}$ & $0.8^{*}$ & $0.5^{*}$ & $0.6^{*}$ & $0.7 *$ & $0.8^{*}$ & $0.5^{*}$ & $0.6^{*}$ & $0.7^{*}$ & $0.8^{*}$ \\
\hline$A_{1}$ & 3 & 3 & 3 & 3 & 5 & 5 & 5 & 5 & 3 & 3 & 3 & 3 & 4 & 5 & 5 & 7 \\
\hline$A_{2}$ & 6 & 6 & 6 & 6 & 8 & 8 & 8 & 8 & 6 & 5 & 5 & 5 & 7 & 8 & 8 & 9 \\
\hline$A_{3}$ & 1 & 1 & 1 & 1 & 1 & 1 & 1 & 1 & 1 & 1 & 2 & 2 & 1 & 1 & 1 & 1 \\
\hline$A_{4}$ & 4 & 4 & 4 & 4 & 6 & 6 & 6 & 6 & 4 & 4 & 4 & 4 & 3 & 4 & 4 & 4 \\
\hline$A_{5}$ & 2 & 2 & 2 & 2 & 2 & 2 & 2 & 2 & 2 & 2 & 1 & 1 & 2 & 2 & 2 & 2 \\
\hline$A_{6}$ & 8 & 8 & 8 & 7 & 7 & 7 & 7 & 7 & 8 & 8 & 8 & 7 & 5 & 3 & 3 & 3 \\
\hline$A_{7}$ & 11 & 11 & 11 & 11 & 11 & 11 & 11 & 11 & 11 & 11 & 11 & 11 & 11 & 10 & 9 & 8 \\
\hline$A_{8}$ & 10 & 10 & 10 & 10 & 10 & 10 & 10 & 10 & 10 & 10 & 10 & 10 & 8 & 6 & 6 & 5 \\
\hline$A_{9}$ & 9 & 9 & 9 & 9 & 9 & 9 & 9 & 9 & 9 & 9 & 9 & 9 & 6 & 7 & 7 & 6 \\
\hline$A_{10}$ & 5 & 5 & 5 & 5 & 3 & 3 & 3 & 3 & 5 & 6 & 6 & 6 & 10 & 11 & 11 & 11 \\
\hline$A_{11}$ & 7 & 7 & 7 & 8 & 4 & 4 & 4 & 4 & 7 & 7 & 7 & 8 & 9 & 9 & 10 & 10 \\
\hline
\end{tabular}

*Showed the weight variety of important degree at each type of logistics park

any influence upon the rank order of location decisions for a potential international logistics park. Based upon the different cases of combinations, i.e. most important for a single logistics park, most important for two logistics parks and most important for three logistics parks, the changes of rank of various potential locations were analyzed.

In the case of most importance for either two or three types of logistics parks, the priority ranking of the 11 international logistics park locations may be obtained. The CFS of Wudo and $\operatorname{Shihjr}\left(A_{3}\right)$ is still the optimum location (Tables 10 and 11).

\section{CONCLUSION}

Each location offers different environmental conditions for the development of the various types of logistics parks. Integrating the activities of logistics functions and cargo flows (import, export, and transshipment), the four types (import/export, transshipment, re-import and re-export) of logistics parks were identified as the foundation to assess development of a location suited to each type of park's logistics functions. The seven criteria respondents were considered when evaluating different types of international logistics parks. The criteria were transportation convenience, rental cost, natural environment, distance from main consumer markets, distance from industrial zones, distance from airport/seaports, and distance from export processing zones.

A fuzzy MCQA decision-making mode was proposed to evaluate the empirical study of locations for developing an international logistics park in northern Taiwan. Eleven locations were evaluated based on the 
Table 10. Location ranking order with two types of logistics park

\begin{tabular}{|c|c|c|c|c|c|c|}
\hline Order & $\begin{array}{c}\text { IM/EX } \\
\& \\
\text { Re-import }\end{array}$ & $\begin{array}{c}\text { IM/EX } \\
\& \\
\text { Transship. }\end{array}$ & $\begin{array}{c}\text { IM/EX } \\
\& \\
\text { Re-export } \\
\end{array}$ & $\begin{array}{c}\text { Re-import } \\
\& \\
\text { Transship. }\end{array}$ & $\begin{array}{c}\text { Re-import } \\
\& \\
\text { Re-export }\end{array}$ & $\begin{array}{c}\text { Transship. } \\
\& \\
\text { Re-export }\end{array}$ \\
\hline 1 & $\mathrm{~A}_{3}$ & $\mathrm{~A}_{3}$ & $\mathrm{~A}_{3}$ & $\mathrm{~A}_{3}$ & $\mathrm{~A}_{3}$ & $\mathrm{~A}_{3}$ \\
\hline 2 & $\mathrm{~A}_{5}$ & $\mathrm{~A}_{5}$ & $\mathrm{~A}_{5}$ & $\mathrm{~A}_{5}$ & $\mathrm{~A}_{5}$ & $\mathrm{~A}_{5}$ \\
\hline 3 & $\mathrm{~A}_{10}$ & $\mathrm{~A}_{1}$ & $\mathrm{~A}_{1}$ & $\mathrm{~A}_{10}$ & $\mathrm{~A}_{10}$ & $\mathrm{~A}_{1}$ \\
\hline 4 & $\mathrm{~A}_{1}$ & $\mathrm{~A}_{4}$ & $\mathrm{~A}_{4}$ & $\mathrm{~A}_{1}$ & $\mathrm{~A}_{4}$ & $\mathrm{~A}_{4}$ \\
\hline 5 & $\mathrm{~A}_{4}$ & $\mathrm{~A}_{2}$ & $\mathrm{~A}_{6}$ & $\mathrm{~A}_{11}$ & $\mathrm{~A}_{1}$ & $\mathrm{~A}_{6}$ \\
\hline 6 & $\mathrm{~A}_{11}$ & $\mathrm{~A}_{10}$ & $\mathrm{~A}_{2}$ & $\mathrm{~A}_{4}$ & $\mathrm{~A}_{11}$ & $\mathrm{~A}_{2}$ \\
\hline 7 & $\mathrm{~A}_{2}$ & $\mathrm{~A}_{11}$ & $\mathrm{~A}_{9}$ & $\mathrm{~A}_{2}$ & $\mathrm{~A}_{6}$ & $\mathrm{~A}_{9}$ \\
\hline 8 & $\mathrm{~A}_{6}$ & $\mathrm{~A}_{6}$ & $\mathrm{~A}_{10}$ & $\mathrm{~A}_{6}$ & $\mathrm{~A}_{9}$ & $\mathrm{~A}_{11}$ \\
\hline 9 & $\mathrm{~A}_{9}$ & $\mathrm{~A}_{9}$ & $\mathrm{~A}_{11}$ & $\mathrm{~A}_{9}$ & $\mathrm{~A}_{2}$ & $A_{8}$ \\
\hline 10 & $A_{8}$ & $A_{8}$ & $A_{8}$ & $A_{8}$ & $A_{8}$ & $\mathrm{~A}_{10}$ \\
\hline 11 & $\mathrm{~A}_{7}$ & $\mathrm{~A}_{7}$ & $\mathrm{~A}_{7}$ & $\mathrm{~A}_{7}$ & $\mathrm{~A}_{7}$ & $\mathrm{~A}_{7}$ \\
\hline
\end{tabular}

Table 11. Location ranking order with three types of logistics park

\begin{tabular}{|c|c|c|c|c|}
\hline Order & $\begin{array}{c}\text { IM/EX } \\
\& \\
\text { Re-import } \\
\& \\
\text { Transship. }\end{array}$ & $\begin{array}{c}\mathrm{IM} / \mathrm{EX} \\
\& \\
\text { Re-import } \\
\& \\
\text { Re-export }\end{array}$ & $\begin{array}{c}\text { IM/EX } \\
\& \\
\text { Transship. } \\
\& \\
\text { Re-export }\end{array}$ & $\begin{array}{c}\text { Re-import } \\
\& \\
\text { Transship. } \\
\& \\
\text { Re-export }\end{array}$ \\
\hline 1 & $\mathrm{~A}_{3}$ & $\mathrm{~A}_{3}$ & $\mathrm{~A}_{3}$ & $\mathrm{~A}_{3}$ \\
\hline 2 & $\mathrm{~A}_{5}$ & $\mathrm{~A}_{5}$ & $\mathrm{~A}_{5}$ & $\mathrm{~A}_{5}$ \\
\hline 3 & $\mathrm{~A}_{1}$ & $A_{1}$ & $\mathrm{~A}_{1}$ & $\mathrm{~A}_{1}$ \\
\hline 4 & $\mathrm{~A}_{10}$ & $\mathrm{~A}_{4}$ & $\mathrm{~A}_{4}$ & $\mathrm{~A}_{4}$ \\
\hline 5 & $\mathrm{~A}_{4}$ & $\mathrm{~A}_{10}$ & $\mathrm{~A}_{6}$ & $\mathrm{~A}_{10}$ \\
\hline 6 & $\mathrm{~A}_{11}$ & $\mathrm{~A}_{11}$ & $\mathrm{~A}_{2}$ & $\mathrm{~A}_{11}$ \\
\hline 7 & $\mathrm{~A}_{2}$ & $\mathrm{~A}_{6}$ & $\mathrm{~A}_{10}$ & $\mathrm{~A}_{6}$ \\
\hline 8 & $\mathrm{~A}_{6}$ & $\mathrm{~A}_{2}$ & $\mathrm{~A}_{9}$ & $\mathrm{~A}_{2}$ \\
\hline 9 & $\mathrm{~A}_{9}$ & $\mathrm{~A}_{9}$ & $\mathrm{~A}_{11}$ & $\mathrm{~A}_{9}$ \\
\hline 10 & $\mathrm{~A}_{8}$ & $\mathrm{~A}_{8}$ & $\mathrm{~A}_{8}$ & $\mathrm{~A}_{8}$ \\
\hline 11 & $\mathrm{~A}_{7}$ & $\mathrm{~A}_{7}$ & $\mathrm{~A}_{7}$ & $\mathrm{~A}_{7}$ \\
\hline
\end{tabular}

perception of logistics professionals of their ability to meet evaluation criteria. Results show that CFS of Wudo and Shihjr, CKS International Airport, and Keelung Port were the preferred investment locations. Finally, we separately analyze the impact of different combination of potential locations for developing an international logistics park on their evaluation ranking.

The location decision-making of international logistics park should take into account the influence of multiple criteria and uncertainties. Traditional MCQA method does not allow decision-makers to make subjective judgments via linguistics variables that are fuzzy in nature. However, the application of crisp values has made it difficult to make judgments in practical applications. With the introduction of a fuzzy MCQA method in collaboration with fuzzy grade measurement, fuzzy grade classification and the MCQA method, decision-makers are only required to judge the satisfaction grade of alternatives rather than granting scores. The method makes judgment in a time saving and efficient way, while maintaining the advantages of a traditional MCQA method. Such an evaluation of locations for developing international logistics zones in northern Taiwan may aid international logistics zone planners in their selection of a location for development.

The limitations of this study suggest several directions for future research. First, this research was limited to examining evaluation criteria based on the perspective of Taiwanese firms. Investors or respondents from other nations may perceive such criteria differently. Future research should include government officials and agencies. Second, this research uses MCQAI, 
which is based upon the satisfaction of decision-makers. In the future, MCQAII should be applied to take into account both the concordance and discordance.

\section{REFERENCES}

1. Armijo, R., Casti, J., and Duckstein, L., "Multicriteria Water Resources System Design by Q-Analysis," Joint TIMS/ORSA Conference, New Orleans, LA (1979).

2. Atkin, R.H., Mathematical Structure in Human Affairs, Heinemann, London (1974).

3. Atkin, R.H. and Witten, I.H., "A Multi-Dimensional Approach to Positional Chess," International Journal of Man-Machine Studies, Vol. 7, No. 6, pp. 727-750 (1975).

4. Bellman, R.E. and Zadel, L.A., "Decision-Making in a Fuzzy Environment," Management Science, Vol. 17, No. 4, pp. 141-164 (1970).

5. Chen, S.J. and Hwang, C.L., Fuzzy Multiple Attribute Decision Making: Methods and Applications, SpringerVerlag, New York (1992).

6. Churchill, G.A., Marketing Research: Methodological Foundation, The Dryden Press, New York (1991).

7. Chin, C., Duckstein, L., and Wymore, M.L., "Factory Automation Project Selection Using Multicriteria QAnalysis," Applied Mathematics and Computation, Vol. 46, No. 2, pp. 107-126 (1991).

8. Chopra, S., "Designing the Distribution Network in a Supply Chain," Transportation Research Part E, No. 39, pp. 123-140 (2003).

9. David, L. and Duckstein, L., "Multicriteria Ranking of Alternative Long-Range Water Resource Systems," Water Resource Bulletin, No. 13, pp. 731-754 (1997).

10. David, S.L., Phillip, K., Edith, S.L., Designing and Managing the Supply Chain, McGraw Hill, New York (2005).

11. Duckstein, L. and Kempf, J., "Multicriteria $Q$-analysis for Plan Evaluation," in Nijkamp, P. and Spronk, J. (eds.), Multiple Criteria Analysis, Gower, Hampshire, England, pp. 87-99 (1981).

12. Duckstein, L., "Evaluation of the Performance of a Distribution System by Q-Analysis," Applied Mathematics and Computation, No. 13 (1\&2), pp. 173-184 (1983).

13. Duckstein, L., Bartels, P.H., and Weber, J.E., "Organization of a Knowledge Base by Q-analysis," Applied Mathematics and Computation, Vol. 26, No. 4, pp. 289-301 (1988)

14. Duckstein, L., Nobe, S.A., "Q-Analysis for Modeling and Decision Making," European Journal Operational Research, No. 103, pp. 411-425 (1997).

15. Eder, G., Duckstein, L., and Nachtnebl, H.P., "Ranking Water Resource Projects and Evaluating Criteria by Multicriteria Q-Analysis: an Austrian Case Study," Journal Multi-criteria Decision, Vol. 6, pp. 259-271 (1997).
16. Glimour, P., "Customer Service: Variousiating by Market Segment," International Journal of Physical Distribution and Materials Management, Vol. 12, No. 3, pp. 37-44 (1982).

17. Hiessl, H., Duckstein, L., and Plate, E.J., "Multiobjective Q-Analysis with Concordance and Discordance Concepts," Applied Mathematics and Computation, Vol. 17, No. 2, pp. 107-122 (1985).

18. Kaufmann, A. and Gupta, M.M., Introduction to Fuzzy Arithmetic, Ban Nostrand, New York (1985).

19. Lambert, D.M. and Harrington, T.C., "Establishing Customer Service Strategies within the Marketing Mix: More Empirical Evidence," Journal of Business Logistics, Vol. 10, No. 2, pp. 44-60 (1989).

20. Lee, H.S., Chou, M.T., and Kuo, S.G., "Evaluating Port Efficiency in Asia Pacific Region with Recursive Data Envelopment Analysis," Journal of the Eastern Asia Society for Transportation Studies, pp. 544-559 (2005).

21. Lu, C.S., "Market Segment Evaluation and International Distribution Centers," Transportation Research Part E, No. 39, pp. 49-60 (2003).

22. Oum, T.H. and Park, J.H., "Multinational Firms' Location Preference for Regional Distribution Centers: Focus on the Northeast Asian Region," Transportation Research Part E, Vol. 40, pp. 101-121 (2004).

23. Picard J., "Physical Distribution Organization in Multinationals: the Position of Authority," International Journal of Physical Distribution and Material Management, Vol. 27, No. 56, pp. 292-305 (1997).

24. Piet, A., Slats, B., Joseph, B., Evers, J.M., and Gert, D., "Logistic Chain Modeling," European Journal Operational Research, No. 87, pp. 1-20 (1995).

25. Prahalad, C. and Doz, Y., The Multinational Mission: Balancing Local Demands and Global Vision, Free press, New York (1987).

26. Saaty, T.L., The Analytic Hierarchy Process, McGrawHill, New York (1980).

27. Sheu, J.B., "A Hybrid Fuzzy-Based Approach for Identifying Global Logistics Strategies," Transportation Research Part E, No. 40, pp. 39-61 (2004).

28. Starr, M. and Zeleny, M., "MCDM: State and Future of the Arts," in Starr, M. and Zeleny, M. (eds.), Multiple Criteria Decision Making, Amsterdam Publishing, NorthHolland, pp. 179-210 (1977).

29. Tai, H.H., Hwang, C.C., "Analysis of Hub Port Choice for Container Trunk Lines in East Asia," Journal of the Eastern Asia Society for Transportation Studies, pp. 907-919 (2005).

30. Teng, J.Y. and Tzeng, G.H., "Fuzzy Multicriteria Ranking of Urban Transportation Investment Alternatines," Transportation Planning and Technology, No. 20, pp. 15-31 (1996).

31. Teng, J.Y., The Project Evaluation of Army Technical Research (Report No. NSC 86-2623-D211-001), Huafan 
University, Taiwan, R.O.C. (1997).

32. Teng, J.Y. and Tzeng, G.H., "Transportation Investment Project Selection Using Fuzzy Multiobjection Programming," Fuzzy Sets and Systems, Vol. 96, pp. 259-280 (1998).

33. Tao, H.O. and Park, J.H., "Multinational Firms' Location Preference for Regional Distribution Centers: Focus on the Northeast Asian Region," Transportation Research Part E, Vol. 40, pp. 101-121 (2004).

34. Vos, B., van den Berg, E., "Assessing International Allocation Strategies," International Journal of Logis- tics Management, Vol. 7, No. 2, pp. 69-84 (1996).

35. Webster, C., "Can Customers Be Segmented on the Basis of Their Customer Service Quality Expertations," The Journal of Services Marketing, Vol. 3, No. 2, pp. 3553 (1989).

36. Yeo, K.T. and Song, D.W., "An Evaluation of Container Ports in China and Korea with the Analytic Hierarchy Process," Journal of the Eastern Asia Society for Transportation Studies, Vol. 5, October, pp. 726-741 (2003).

37. Zadeh, L.A., "Fuzzy Sets," Information and Control, Vol. 8, pp. 338-353 (1965). 